\title{
Placing unprecedented recent fir growth in a European-wide and Holocene-long context
}

\author{
Ulf Büntgen ${ }^{1,2,3^{*}}$, Willy Tegel ${ }^{4}$, Jed O Kaplan ${ }^{5}$, Marcus Schaub ${ }^{1}$, Frank Hagedorn ${ }^{1}$, Matthias Bürgi ${ }^{1}$, \\ Rudolf Brázdili, ${ }^{3,6}$, Gerhard Helle ${ }^{7}$, Marco Carrer ${ }^{8}$, Karl-Uwe Heussner ${ }^{9}$, Jutta Hofmann $^{10}$, Raymond Kontic ${ }^{11}$, \\ Tomáš Kyncl ${ }^{12}$, Josef Kyncl ${ }^{12}$, J Julio Camarero ${ }^{13,14}$, Willy Tinner ${ }^{2,15}$, Jan Esper ${ }^{16}$, and Andrew Liebhold ${ }^{17}$
}

Forest decline played a pivotal role in motivating Europe's political focus on sustainability around 35 years ago. Silver fir (Abies alba) exhibited a particularly severe dieback in the mid-1970s, but disentangling biotic from abiotic drivers remained challenging because both spatial and temporal data were lacking. Here, we analyze 14136 samples from living trees and historical timbers, together with 356 pollen records, to evaluate recent fir growth from a continent-wide and Holocene-long perspective. Land use and climate change influenced forest growth over the past millennium, whereas anthropogenic emissions of acidic sulfates and nitrates became important after about 1850 . Pollution control since the 1980s, together with a warmer but not drier climate, has facilitated an unprecedented surge in productivity across Central European fir stands. Restricted fir distribution prior to the Mesolithic and again in the Modern Era, separated by a peak in abundance during the Bronze Age, is indicative of the long-term interplay of changing temperatures, shifts in the hydrological cycle, and human impacts that have shaped forest structure and productivity.

Front Ecol Environ 2014; 12(2): 100-106, doi:10.1890/130089 (published online 18 Dec 2013)

$\mathrm{E}^{\mathrm{n}}$ nvironmental political action catalyzed about 35 years ago in Europe, with the widespread public perception that forests were dying as a result of air pollution and related acid deposition (Schütt and Cowling 1985; Innes 1987; Kandler and Innes 1995). This apparent decline, considered to be unprecedented in a broad spatiotemporal context, stimulated new pollution control legislation and promoted environmental awareness. However, scientific curiosity about this subject gradually waned after a decade of intensive research in conjunction with evidence of forest ecosystem recovery (Spiecker 1995).

Reports of crown dieback and declining tree growth during the mid-1970s were mostly derived from individual stands of silver fir (Abies alba; Kandler and Innes 1995). These changes were linked with local to regional assessments of sulfur emissions, drought, insect and pathogen outbreaks, and soil acidification. However, quantifying and fully understanding the reasons for these variations in forest health were complicated by a general lack of long and well replicated tree-ring width chronologies (ie annually resolved and properly dated time series of radial stem thickening) and the difficulty of disentangling the biotic and abiotic factors that might be responsible for the observed changes. In other analyses of environmental change, chronologies of tree-ring width have been extremely useful in characterizing long-term variability in climatological and ecological conditions and

\footnotetext{
${ }^{1}$ Swiss Federal Research Institute WSL, Birmensdorf, Switzerland *(buentgen@wsl.ch); ${ }^{2}$ Oeschger Centre for Climate Change Research, Bern, Switzerland; ${ }^{3}$ Global Change Research Centre AS CR, Brno, Czech Republic; ${ }^{4}$ Institute for Forest Growth IWW, University of Freiburg, Freiburg, Germany; continued on p 106
}

the effects on forest productivity and vigor (Büntgen et al. 2011b, 2013). Unfortunately, extensive temporal and spatial datasets on silver fir growth have not been available, and this has limited the opportunities for understanding past changes in the species' growing conditions across Europe.

Here, we compile ring-width measurements from living fir trees and historical construction timbers throughout Europe and use them to quantify trends in forest productivity over the past millennium. We also utilize paleobotanical pollen profiles to reconstruct trends in fir land cover over the entire Holocene. This novel, multi-proxy (treering/pollen) approach provides a much broader and longer term perspective on the highly publicized Central European forest decline of the 1970s and therefore allows for an improved understanding of the external drivers of fir growth and abundance at various spatiotemporal scales.

\section{Methods}

Core and disc samples of 14136 living and historical silver fir trees were collected over the past four decades in Spain, France, Italy, Switzerland, Germany, Poland, Slovakia, Ukraine, and the Czech Republic. All historical samples were obtained from construction timbers that made up the frameworks of roofs and walls in old buildings. Such materials represent a rich source for dendrochronological studies, providing data that go back to medieval times across most of Central Europe (WebFigure 1). (See Büntgen et al. [2011b, 2013] for a more detailed description of the various tree-ring archives that offer a unique source of multi-centennial to millennial-long tree-ring chronologies in Central Europe.) 

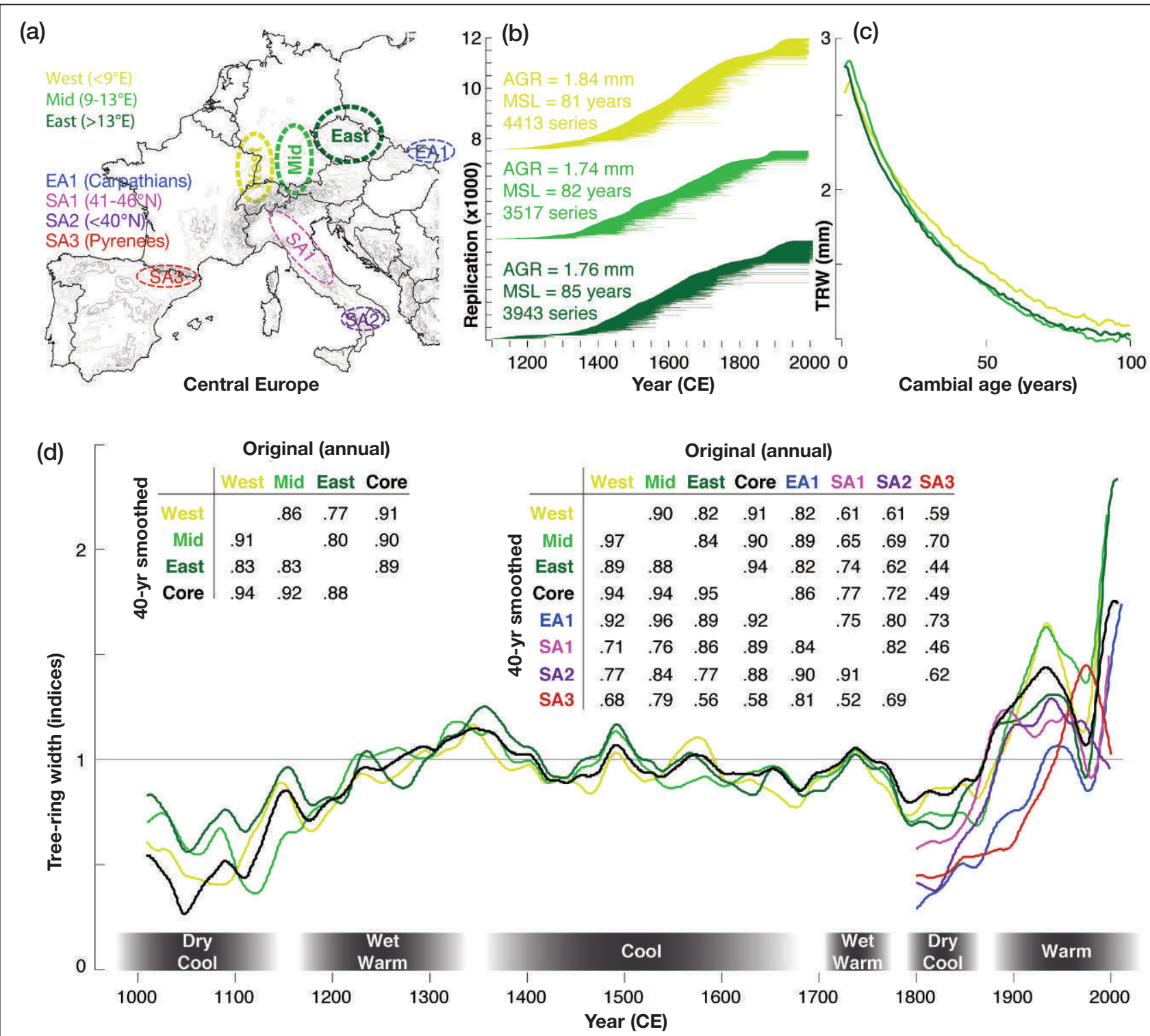

Figure 1. (a) Location of the three core regions of living and historical silver fir sampling that are situated north of the Alpine Arc (West, Mid, and East), as well as the additional four sampling areas near the species-specific distribution limits in the Carpathian Arc (EA1), along the Italian Peninsula (SA1 and SA2), and in the Pyrenees Mountains (SA3). (b) Temporal distribution of the 11873 living and historical fir samples (ie measurement series) from the three core regions, along with information on average growth rate (AGR), mean segment length (MSL), and sample replication. (c) The biological aging trends expressed by the Regional Curve (RC) per region (West, Mid, and East), which shows exponentially decreasing tree-ring widths (TRWs along the $y$ axis) with increasing tree age (years along the $x$ axis). (d) Regional subset chronologies of the three fir core subsets (green), their mean values (black), and the four more marginal chronologies (blue-red). All chronologies were RCS detrended and additionally smoothed with a 40-year lowpass filter. Highly significant correlation coefficients ( $\mathrm{P}<0.00001$ in all cases) of the original (upper right values) and 40-year smoothed (lower left values) chronologies from the three core regions (West, Mid, and East) were computed over the 1133-1996 common period, during which each chronology is replicated by at least 20 series. Additional correlation coefficients, calculated between all core and marginal chronologies over the 1800-1996 industrial period, were also significant $(\mathrm{P}<0.0001)$. The gray horizontal bar at the bottom refers to general Central European climate conditions, as introduced by Büntgen et al. (2011b).

Our compilation of annual-ring-width data spans 962-2011 CE and covers the entire range of silver fir distribution, including three core regions north of the European Alps (West, Mid, and East), as well as fringes in the Carpathian Arc (EA1), northern and southern Italy (SA1 and SA2), and the Pyrenees (SA3) (Figure 1a;
WebFigure 1; WebTable 1). This represents the world's largest dendrochronological dataset for a single conifer species. Samples from the three core regions were exclusively taken from forest stands $<900 \mathrm{~m}$ above sea level (asl), and each contains sequences of at least 50 consecutive rings (Büntgen et al. 2011a, 2012b). Sample sizes, 
aging trends, and growth levels are similar among the core regions (Figure 1, b-d), with significant correlations $\left(r_{1133-1996}=0.77-0.94 ; P<0.00001\right)$, indicating highly synchronized growth behavior. The massively replicated core subsets of 3517-4413 samples each share a high degree of common growth variability (ie internal signal strength; WebFigures 2 and 3). See also Büntgen et al. (2011a, 2012b) for additional information on growth trends and levels among the different regions (WebFigures 2-4).

Geographically averaged instrumental measurements were extracted from a network of meteorological stations across the greater Alpine region (HISTALP; Auer et al. 2007). These records were used to assess changes in the relationship between radial fir growth and monthly temperature means (since $1760 \mathrm{CE}$ ), sunshine duration (since 1880), precipitation totals (since 1800), and cloudiness (since 1840). A suite of 2736 correlation coefficients, together with split-period and moving-window approaches, were applied to detect spatiotemporal instability in the relationship between Central European fir growth and climate variation.

Pre-instrumental indices of temperature and precipitation back to 1500 CE were further derived from documentary evidence, including annals; chronicles; memorial books; visual daily weather observations; private correspondence; illustrated broadsheets; newspapers and journals; pictorial evidence; stall-keepers' and market songs; early scientific papers and communications; epigraphic sources; and early instrumental meteorological measurements (Brázdil et al. 2005). Central European temperature indices were obtained from Dobrovolný et al. (2010), while corresponding precipitation indices were compiled specifically for this study. These data were used to explore associations of annual weather conditions with regional- to continental-scale extremes in radial growth of the silver fir. Individual months were classified on an ordinal scale: -3 (extremely cold/dry), -2 (very cold/dry), $\quad-1$ (cold/dry), 0 (normal), +1 (warm/wet), +2 (very warm/wet), and +3 (extremely warm/wet), with seasonal indices fluctuating from -9 to +9 (WebTable 2; see also Dobrovolný et al. [2010] and Büntgen et al. [2011a] for details).

We used decadal records of sulfur dioxide $\left(\mathrm{SO}_{2}\right)$ and nitrogen oxide $\left(\mathrm{NO}_{\gamma}\right)$ emissions across Europe, extracted from version 2.0 of the Emission Database for Global Atmospheric Research (EDGAR 2.0; van Aardenne et al. 2001), to explore their possible associations with fir growth and vigor back to $1850 \mathrm{CE}$.

Paleoecological evidence of silver fir occurrence was synthesized from the European Pollen Database (Fyfe et al. 2009), the PANGAEA database (www.pangaea.de), values digitized from published pollen diagrams, and personal communications from specific authors (WebTable 3). These pollen records were derived from sediment cores of European lakes, swamps, and bogs. Abies pollen cannot be differentiated at the species level, so records were made at the genus level. The percentage of pollen that was composed of fir pollen at each sampling site was binned into multiple 500-year periods spanning the past 10500 years. Using a 3D thin plate spline method that uses elevation as a third dimension (Collins et al. 2012), we spatially interpolated these values on five arc minute $(\sim 5 \mathrm{~km})$ grid cells. The resulting time sequence of fir distribution maps encompassed the Holocene and was spatially adapted to cover the continent's major drainage basins north of the Alps, and from the Rhine to the Danube.

\section{Results}

Fir growth varied considerably over the past several centuries. Low growth rates occurred prior to $\sim 1200$, from $\sim 1600$ to 1700 , and from 1780 to 1870 , whereas anomalously high growth rates occurred at most sites $\sim 1350$, $\sim 1490$, from $\sim 1880$ to 1950 , and from the mid-1980s to the present (Figure 1; WebFigure 4). Reduced fir growth rates prior to $\sim 1200$ and in the first half of the 19th century coincided with relatively dry and cold periods (Figure 1d), whereas above-average growth rates paralleled periods of an overall wetter and warmer climate (Büntgen et al. 2011b). The relationship between tree age and growth resembles a negative exponential function, characteristic of a species regenerating under relatively open canopy forest structure (WebFigure 2). The appearance of suppressed juvenile growth prior to $\sim 1300$ and in the 19th century indicates relatively higher stand densities during these periods, which, in turn, is suggestive of greater resource competition (Büntgen et al. 2012b).

Growth-climate relationships of all ring-width measurement datasets from the three core regions (West, Mid, and East) remain non-significant overall $(P>0.001)$, with the exception of some spurious agreement between recently increasing trends in temperature and fir growth (Figure 2). Correlation coefficients that are based on six slightly different silver fir chronologies (ie raw measurements, raw measurements after powertransformation, Regional Curve Standardization [RCS] detrending, RCS detrending after power-transformation, negative exponential functions, and 80-year spline functions), 19 monthly and seasonal resolved targets among temperature, sunshine, precipitation, and cloudcover, two independent early and late split periods (1760-1950 and 1951-2007), and three geographical regions (Northwest Alpine Arc, Northeast Alpine Arc, and the Greater Alpine Region) accumulate to growth-climate 2736 pairings (see also Büntgen et al. [2012a] for methodological insight on the so-called "Ensemble Approach"). An array of statistically significant negative correlations with indices of May temperature and springtime sunshine before the mid-20th century indicates the inverse relationship of these two parameters with precipitation and therefore suggests some dependency of fir growth on soil moisture availability at the beginning of the vegetation 
period, in line with the findings of Büntgen et al. (2011a). Nevertheless, a lack of short-term climate sensitivity is evident and possibly reflects transient growth responses to environmental changes, related in part to the fact that all samples from the core regions were collected at $<900 \mathrm{~m}$ asl. The high degree of temporal instability in the obtained growth-climate associations is further emphasized by 31-year moving correlation coefficients (WebFigure 5). Although nonsignificant overall, there is a tendency for increasing positive relationships between fir growth and temperature/sunshine after 1950 (although partly inflated by similar trend behavior), whereas recent correlations with precipitation/cloudcover are decreasing. We also found little similarity between reconstructed April-June precipitation totals and JuneAugust temperature means (WebFigure 6). Nevertheless, there was clear evidence that negative and positive growth extremes have coincided with dry and humid springtime conditions, respectively, during the past 500 years (WebTable 2).

Growth rates among all regions were highly synchronized $\left(r_{1800-1996}=0.44-0.97\right)$ and generally increased during the 1800-1996 industrial era (Figure $3 a)$. There was a synchronous post-1950 ring-width depression, but growth strongly increased from the early 1980s onward, though this was less pronounced in Southern Italy and the Spanish Pyrenees (Figure 3b).

Postglacial forests included only a small fraction of fir trees between $\sim 8000$ and 6000 BCE (Figure 4), after which the relative amount of fir steadily increased. Despite a short depression $\sim 4000 \mathrm{BCE}$, fir pollen continued to increase relative to total terrestrial pollen, reaching a maximum of $\sim 7 \%$ on average $\sim 1000 \mathrm{BCE}$, which preceded a continuous decline during the Common Era.

\section{Discussion}

During the early 1980s, considerable scientific and public attention was directed toward ongoing extensive dieback

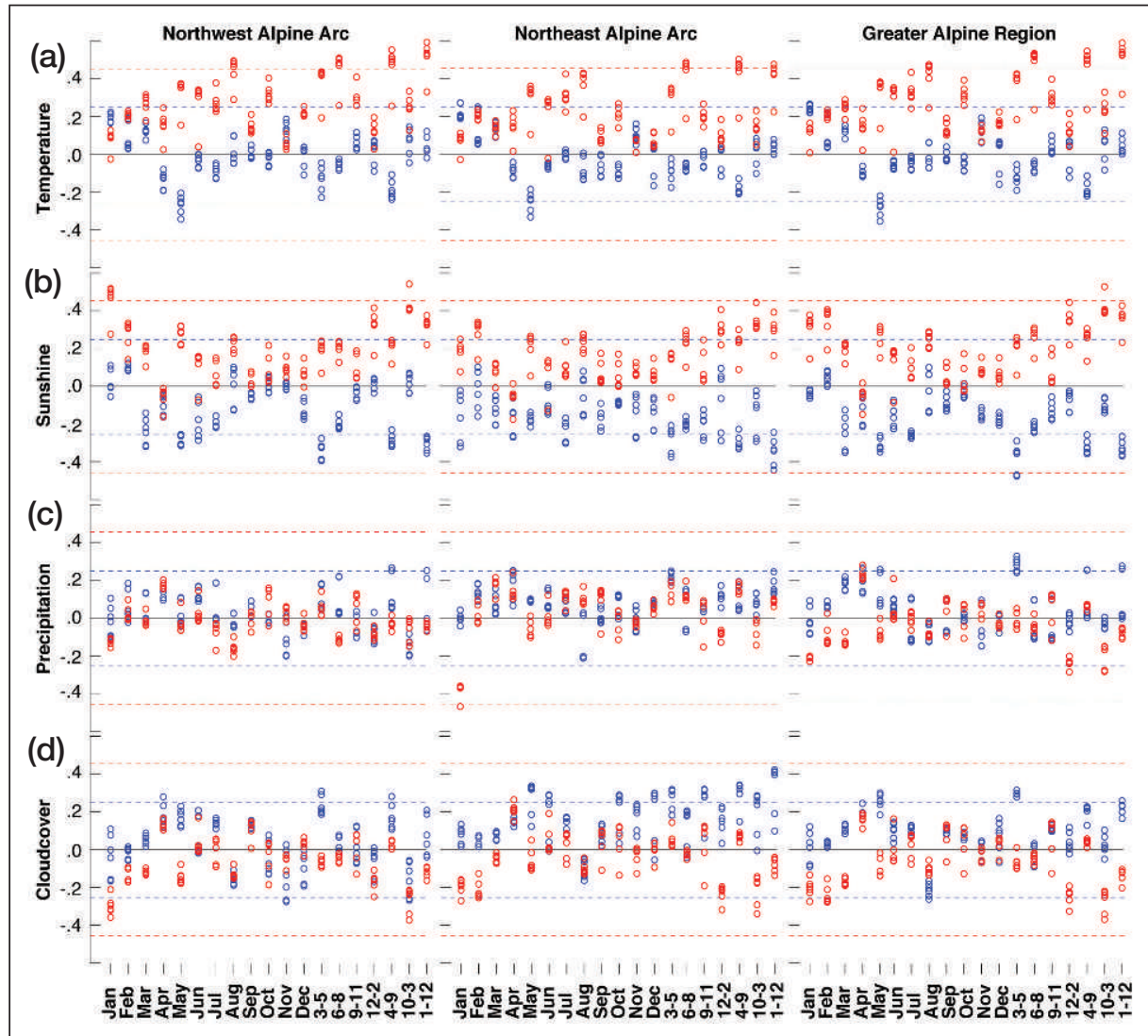

Figure 2. A total of 2736 associations (correlation coefficients) between six slightly different silver fir chronologies and 19 monthly and seasonally resolved climatic targets were calculated over two independent early and late split periods (1760-1950 [blue] and 1951-2007 [red]) and three geographical regions (Northwest Alpine Arc, Northeast Alpine Arc, and the Greater Alpine Region) (Auer et al. 2007). The six fir chronologies - based on raw measurements, raw measurements after power-transformation, RCS detrending, RCS detrending after power-transformation, negative exponential functions, and 80-year spline functions - were calculated from all ring-width measurement series of the three core regions (West, Mid, and East). The monthly (a) temperature, (b) sunshine, (c) precipitation, and cloudcover indices range from January-December, whereas the seven climatologically defined seasonal means include March-May (3-5), June-August (6-8), September-November (9-11), December-February (12-2), April-September (4-9), October-March (10-3), and annual (1-12). Horizontal dashed lines refer to the $99.9 \%$ significance levels, independently calculated for the early and late split periods (blue and red).

in European forest trees, especially silver fir (Schütt and Cowling 1985; Innes 1987; Kandler and Innes 1995). Concern over these declines motivated stricter air-pollution regulation and generated a new political focus on the environment that persists to this day in Europe. Although several studies documented local to regional forest declines during this period, primarily across the central portion of the continent, it is useful to revisit this dieback from a much broader perspective in time and space.

Paleobotanical evidence from pollen profiles (WebTable 3) indicates that fir trees were a fairly small component of postglacial forests from 8000 to $6000 \mathrm{BCE}$ (Figure 4). Fir pollen, however, steadily increased after $\sim 6000 \mathrm{BCE}$, both as a percentage of the total terrestrial assemblage and relative to other arboreal taxa. Range 


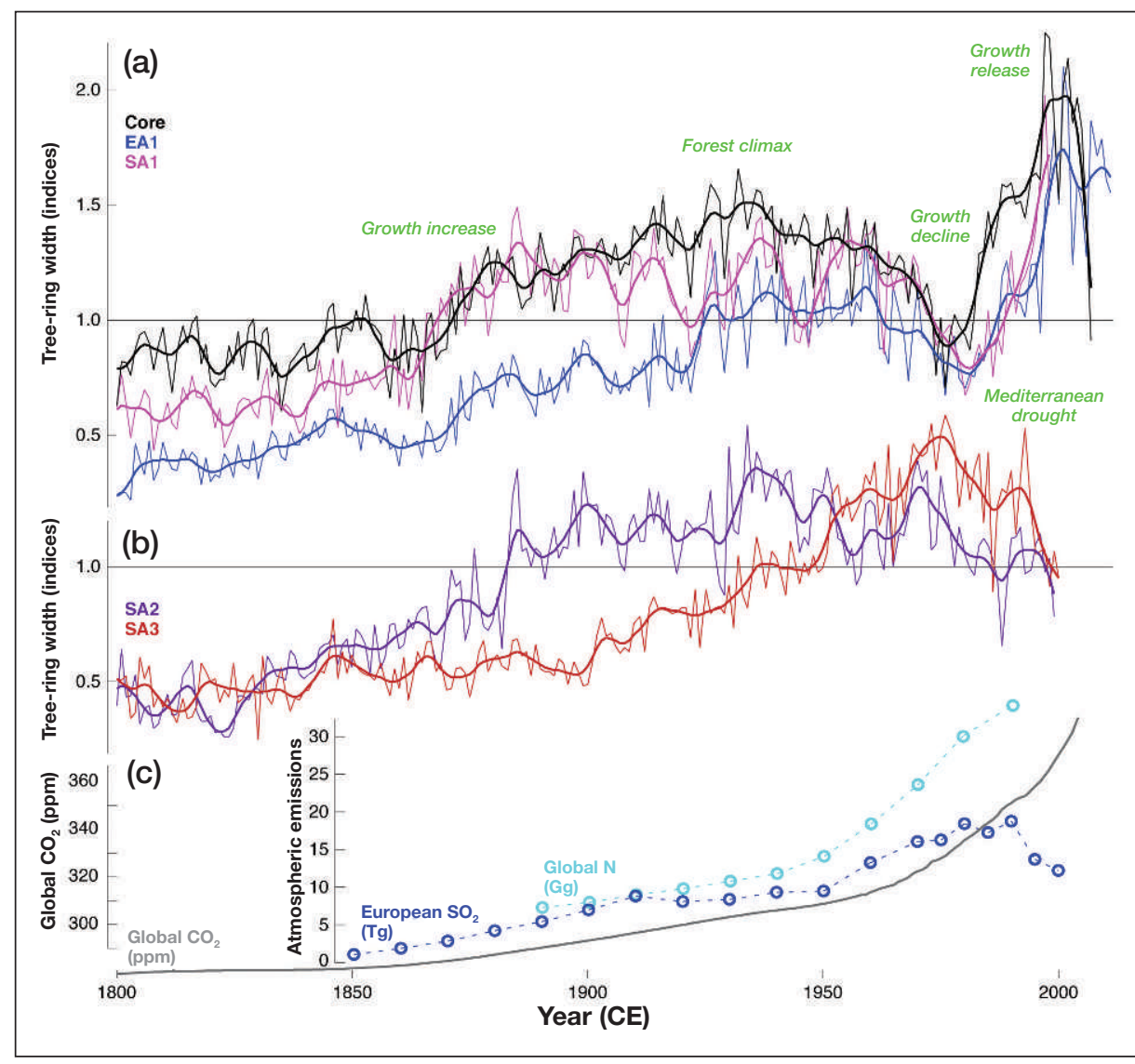

Figure 3. Changes in annual (original unsmoothed data) and decadal (10-year low-pass filtered time series) fir growth across (a) Central Europe and (b) the Mediterranean (SA2 = Southern Italy and SA3 = Pyrenees). (c) Long-term evolution of global nitrogen (N) and atmospheric carbon dioxide $\left(\mathrm{CO}_{2}\right)$ concentrations, as well as European-scale estimates of sulfur dioxide $\left(\mathrm{SO}_{2}\right)$ emissions, which were compiled by van Aardenne et al. (2001). coastal and hilly areas, suggesting high performance of silver fir under conditions warmer than those of today.

Timber harvesting, along with intense woodland grazing and litter collection, influenced the disproportionate decrease in fir abundance long before industrialization. Clear-cutting, as part of intensive forest extraction since the 14th century and especially after the Thirty Years' War ( 1618-1648), root decay, and later smoke damage all contributed to some extent to an accelerated European-wide decline in the 17th century. Fir regeneration was suppressed by competition from spruce, beech, and pine, which were intensively planted from the 18th and early19th century onwards, following clear-cutting (Bürgi and Schuler 2003). Exploitative land-use/landcover changes may partially explain declining fir abundance from medieval times until $\sim 1840$.

Despite the millennium-long decline in fir populations, productivity has substantially increased Europe-wide during the past two centuries (Figure 3).

expansion and increased abundance were likely triggered by a shift to moister conditions after the " $8.2 \mathrm{k}$ event" (Tinner and Lotter 2006). Despite the declining total arboreal pollen percentage after $\sim 4000 \mathrm{BCE}$, fir pollen continued to increase until $\sim 1000 \mathrm{BCE}$, probably due to increasingly moist European conditions (Feurdean and Willis 2008). This prehistoric fir peak was followed by a continuous decline that has lasted until the present.

This long-term trend is corroborated by dendroarchaeological evidence - from several Swiss Neolithic lakeside dwellings - in the form of a vast abundance of fir wood 3500 BCE (Figure 4). Investigations of northern Alpine settlements revealed thousands of fir logs used for Bronze Age and newer construction. Interestingly, fir wood not only dominated roof construction and skeleton framing during the past millennium but also was frequently used in assembling ancient Roman barrels, wells, and ships. However, increasing forest extraction, agricultural expansion, and competition from beech probably diminished total silver fir cover during recent millennia. Prior to the conversion of pristine forests into fire-prone macchiadominated ecosystems (densely growing evergreen Mediterranean-type vegetation) at 4000-3000 BCE (Colombaroli et al. 2007), fir was abundant in Mediterranean
This boost in productivity may be attributed in part to the advent of less intense practices of woodland utilization. However, these changes alone cannot explain the synchronous increase in productivity, because different strategies were applied at different times and at different national, county, and even communal levels. Clear-cutting after artificial spruce regeneration may have affected the mid- and eastern core subsets in a similar manner. For example, Swiss federal laws established in 1870 banned forest grazing (to which fir is particularly sensitive), and clear-cutting was abandoned shortly after the beginning of the 20th century (Bürgi and Schuler 2003), when various forms of group cutting were promoted. Selective logging of fir was applied in the Venetian Republic of Northern Italy, and fir grazing in combination with coppicing of the broadleaf species was applied in the Italian Piedmont.

Industrialization presumably promoted fir recovery beginning around the mid-19th century, since wood fuel was gradually replaced by fossil fuels, particularly since the 1950s when globalization led to the abandonment of local semi-autarkic (ie semi-self-sufficient) agricultural production systems throughout the mountainous areas of Europe. The long-term ring-width increase that occurred from $\sim 1840$ to 1940 in almost all fir habitats across the 
continent was therefore probably stimulated by a combination of land-use practices and warming without drying, as well as through fertilization by nitrogen (N) and carbon dioxide $\left(\mathrm{CO}_{2}\right)$ (Figure 3c; Körner 2006; Thomas et al. 2008). In contrast, sulfur (in the form of $\mathrm{SO}_{2}$ ) deposition caused negative feedbacks, with soil acidification inducing aluminum toxicity to fine roots (van Breemen et al. 1982). Rising atmospheric $\mathrm{CO}_{2}$ concentrations from pre-industrial levels in the mid-20th century (280-320 parts per million [ppm]) potentially influenced the continental-wide growth enhancement (Körner 2006). The absolute change of $\sim 40$ ppm in atmospheric $\mathrm{CO}_{2}$ prior to the mid-20th century possibly initiated an effect on tree growth similar to that of the most recent increase from 315-385 ppm, which was partly masked by pollutants $\left(\mathrm{SO}_{2}\right.$, $\mathrm{NO}_{x}$ ) and tropospheric ozone $\left(\mathrm{O}_{3}\right)$ after $\sim 1950$, for instance.

A substantial and synchronous decline in fir productivity, despite the ongoing multi-century trend of increasing growth, is clearly evident during the 1970s, followed by a recovery phase (Figure 3a). The late-1970s' depression coincided with increasing $\mathrm{SO}_{2}$ emissions (Figure 3c). Air pollution not only directly harmed needle growth but also may have prompted lag effects via soil acidification. Moreover, it is probable that tree nutrition became imbalanced with disproportionate $\mathrm{N}$ uptake compared to base cations by elevated N deposition (Schulze 1989). The success of recent pollution mitigation initiatives is indicated by a rapid surge in Central European growth after $\sim 1982$, with the effects of forest management, climate warming, and atmospheric fertilization potentially also amplifying this boost. In contrast, Mediterranean forest ecosystems suffer from a long-term drying trend since the 1970s (Figure 3b). Fir growth in the Spanish Pyrenees likely showed local drought-induced post-1980s decline (Figure 3a), and affected stands were not able to increase their water-use efficiency (Camarero et al. 2011; Linares and Camarero 2012), despite rising atmospheric $\mathrm{CO}_{2}$ concentrations.

There has possibly been some underestimation of the 1970s Central European forest dieback and overestimation of the subsequent growth release as a result of tree-ring sampling bias, given that the 20th century is represented by surviving trees only, which have recently grown under lower and wider canopy structures in more open habitats. Estimates of early industrial pollution and the resulting atmospheric composition are also not sufficiently resolved in space and time to accurately explain any direct vegetation responses; likewise, the historical development of acidification in different soil types is not well understood. The relative importance of forest insect and disease outbreaks to observed growth declines observed here remains unclear due to the lack of consistent regional outbreak records. The possibility that insect pests or fungal pathogens functioned as either primary or secondary factors contributing to the mid-1970s fir decline still represents an unanswered question (Houston 1987), particularly considering that these agents may have interacted with the extreme drought that occurred in 1976 (Spiecker 1995).

This study suggests that silver fir growth, in contrast with the growth of other tree species, will benefit from a projected warmer but not drier climate in mesic areas, whereas more southern habitats near the species' Mediterranean distribution limit are already exhibiting drought-induced growth depression, which will become even more critical in a drier future. These spatially diverse trends, projected to continue under climate change, could potentially be important to recent largescale estimates of terrestrial carbon budgets, and thus should be considered for inclusion in certain ecological and biogeochemical models. 


\section{Acknowledgements}

We thank ZAMG and CRU for making instrumental data available, $\mathrm{P}$ Collins for processing pollen data, and all ITRDB contributors and the KNMI climate explorer team. UB was also supported by the Operational Programme of Education for Competitiveness of the Ministry of Education, Youth and Sports of the Czech Republic (Project No CZ.1.07/2.3.00/20.0248).

\section{References}

Auer I, Böhm R, Jurkovic A, et al. 2007. HISTALP - historical instrumental climatological surface time series of the greater Alpine region 1760-2003. Int J Climatol 27: 17-46.

Brázdil R, Pfister C, Wanner H, et al. 2005. Historical climatology in Europe - the state of the art. Climatic Change 70: 363-430.

Büntgen U, Brazdil R, Heussner K-U, et al. 2011a. Combined dendro-documentary evidence of Central European hydroclimatic springtime extremes over the last millennium. Quat Sci Rev 30: 3947-59.

Büntgen U, Tegel W, Nicolussi K, et al. 2011b. 2500 years of European climate variability and human susceptibility. Science 331: 578-82.

Büntgen U, Kaczka RJ, Trnka M, and Rigling A. 2012a. Ensemble estimates reveal a complex hydroclimatic sensitivity of pine growth at Carpathian cliff sites. Agr Forest Meteorol 160: 100-09.

Büntgen U, Tegel W, Heussner K-U, et al. 2012b. Effects of sample size in dendroclimatology. Clim Res 53: 263-69.

Büntgen U, Kyncl T, Ginzler C, et al. 2013. Filling the Eastern European gap in millennium-long temperature reconstructions. P Natl Acad Sci USA 110: 1773-78.

Bürgi M and Schuler A. 2003. Driving forces of forest management - an analysis of regeneration practices in the forests of the Swiss Central Plateau during the 19th and 20th century. Forest Ecol Manag 176: 173-83.

Camarero JJ, Bigler C, Linares JC, and Gil-Pelegrin E. 2011. Synergistic effects of past historical logging and drought on the decline of Pyrenean silver fir forests. Forest Ecol Manag 262: 759-69.

Collins PM, Davis BAS, and Kaplan JO. 2012. The mid-Holocene vegetation of the Mediterranean region and southern Europe, and comparison with the present day. J Biogeogr 39: 1848-61.

Colombaroli D, Marchetto A, and Tinner W. 2007. Long-term interactions between Mediterranean climate, vegetation and fire regime at Lago di Massaciuccoli (Tuscany, Italy). J Ecol 95: 755-70.

Dobrovolný P, Moberg A, Brazdil R, et al. 2010. Monthly, seasonal and annual temperature reconstructions for Central Europe derived from documentary evidence and instrumental records since AD 1500. Climatic Change 101: 96-107.

Feurdean A and Willis KJ. 2008. Long-term variability of Abies alba in NW Romania: implications for its conservation management. Divers Distrib 14: 1004-17.

Fyfe RM, de Beaulieu JL, Binney H, et al. 2009. The European Pollen Database: past efforts and current activities. Veg Hist Archaeobot 18: 417-24.
Houston DR. 1987. Forest tree declines of past and present: current understanding. Can J Plant Pathol 9: 4349-60.

Innes JL. 1987. Air pollution and forestry. Forestry Commission Bulletin number 70. London, UK: HMSO.

Kandler O and Innes JL. 1995. Air pollution and forest decline in Central Europe. Environ Pollut 90: 171-80.

Körner C. 2006. Plant $\mathrm{CO}_{2}$ responses: an issue of definition, time and resource supply. New Phytol 172: 393-411.

Linares JC and Camarero JJ. 2012. From pattern to process: linking intrinsic water-use efficiency to drought-induced forest decline. Glob Change Biol 18: 1000-15.

Schulze ED. 1989. Air pollution and forest decline in a spruce (Picea abies) forest. Science 244: 776-83.

Schütt P and Cowling EB. 1985. Waldsterben, a general decline of forests in Central Europe: symptoms, development, and possible causes. Plant Dis 69: 548-58.

Spiecker H. 1995. Growth dynamics in a changing environment long-term observations. Plant Soil 168: 555-61.

Thomas RQ, Canham CD, Weathers KC, and Goodale CL. 2008. Increased tree carbon storage in response to nitrogen deposition in the US. Nat Geosci 3: 13-17.

Tinner W and Lotter AF. 2006. Central European vegetation response to abrupt climate change at 8.2 ka. Geology 29: 551-54.

van Aardenne J, Dentener F, Olivier J, et al. 2001. A $1^{\circ} \times 1^{\circ}$ resolution data set of historical anthropogenic trace gas emissions for the period 1890-1990. Global Biogeochem Cy 15: 909-28.

van Breemen N, Burrough PA, Velthorst EV, et al. 1982. Soil acidification from atmospheric ammonium sulphate in forest canopy throughfall. Nature 299: 548-50.

\section{Author contributions}

UB and WTegel designed the study and analyzed the data with input from all authors. UB, WTegel, K-UH, JH, RK, $\mathrm{TK}, \mathrm{JK}, \mathrm{JJC}$, and MC sampled and compiled tree-ring measurements. JOK and RB provided pollen and documentary data, respectively. UB, AL, and WTegel wrote the article with input from all authors.

${ }^{5}$ Environmental Engineering Institute, Ecole Polytechnique Fédérale de Lausanne, Lausanne, Switzerland; 'Institute of Geography, Masaryk University, Brno, Czech Republic; ${ }^{7}$ Helmholtz Centre Potsdam, GFZ German Research Centre for Geosciences, Potsdam, Germany; ${ }^{8}$ University of Padova, Dip TeSAF, Legnaro, Italy; ${ }^{9}$ German Archaeological Institute DAI, Berlin, Germany; ${ }^{10}$ Jahrringlabor Hofmann, Nürtingen, Germany; ${ }^{11}$ Labor Dendron, Basel, Switzerland; ${ }^{12}$ Moravian Dendro-Labor, Brno, Czech Republic; ${ }^{13}$ ARAID-Instituto Pirenaico de Ecología IPE-CSIC, Zaragoza, Spain; ${ }^{14}$ Department of Ecology, University of Barcelona, Barcelona, Spain; ${ }^{15}$ Institute of Plant Sciences, University of Bern, Bern, Switzerland; ${ }^{16}$ Department of Geography, Johannes Gutenberg University, Mainz, Germany; ${ }^{17}$ Northern Research Station, USDA Forest Service, Morgantown, WV 